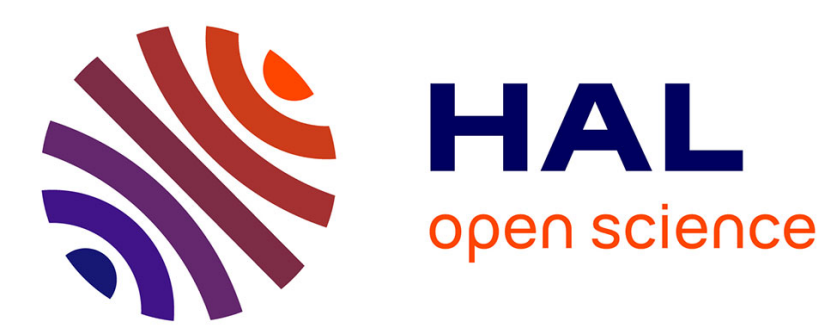

\title{
STANDARDIZED BAUER PVDF PIEZOELECTRIC POLYMER SHOCK GAUGE
}

\author{
L. Lee, R. Graham, F. Bauer, R. Reed
}

\section{To cite this version:}

L. Lee, R. Graham, F. Bauer, R. Reed. STANDARDIZED BAUER PVDF PIEZOELECTRIC POLYMER SHOCK GAUGE. Journal de Physique Colloques, 1988, 49 (C3), pp.C3-651-C3-657. 10.1051/jphyscol:1988391 . jpa-00227814

\section{HAL Id: jpa-00227814 https://hal.science/jpa-00227814}

Submitted on 1 Jan 1988

HAL is a multi-disciplinary open access archive for the deposit and dissemination of scientific research documents, whether they are published or not. The documents may come from teaching and research institutions in France or abroad, or from public or private research centers.
L'archive ouverte pluridisciplinaire HAL, est destinée au dépôt et à la diffusion de documents scientifiques de niveau recherche, publiés ou non, émanant des établissements d'enseignement et de recherche français ou étrangers, des laboratoires publics ou privés. 
JOURNAL DE PHY\$IQUE

Colloque C3, Supplément au $n^{\circ} 9$, Tome 49, septembre 1988

\title{
STANDARDIZED BAUER PVDF PIEZOELECTRIC POLYMER SHOCK GAUGE
}

\author{
L.M. LEE (1), R.A. GRAHAM* (2), F. BAUER* and R.P. REED*, (2) \\ Ktech Corporation, 901, Pennsylvania Avenue NE, Albuquerque, \\ NM 87110, U.S.A. \\ "Sandia National Laboratories, PO Box 5800. Albuquerque, \\ NM 87185, U.S.A. \\ **Institut Saint-Louis, F-68300 Saint-Louis, France
}

\begin{abstract}
RESUME : Afin de réaliser des mesures d'ondes de choc on a besoin d'un capteur standardisé pouvant répondre à des chargements par choc dans une grande gamme de contraintes (de 0.2 à $50 \mathrm{GPa}$ ). Un programme coopératif a été réalisê par nos laboratoires afin de fournir une jauge à film polymère (PVDF) qui soit bien comprise et très reproductible pour étudier le chargement et la relaxation par onde de contrainte. La source de matériau polymère et le traitement électrique sont basés sur des travaux antérieurs de Bauer. La réponse au choc d'une jauge de contrainte standardisée piézoélectrique PVDF produite par SNLA/Ktech, ISL et l'industrie a été mesurée lors d'essais par ondes de choc contrôlés en útilisant un canon à gaz comprimé. Les mesures de la réponse faites dans le domaine 0.3 à $46 \mathrm{GPa}$ montrent un excellent accord entre les jauges produites par ces trois fabricants différents. Ces expériences démontrent qu'une jauge de contrainte en PVDF reproductible et bien connue peut être prođuite si des spécifications strictes sont suivies. Ces expériences démontrent que les jauges en PVDF peuvent fonctionner de manière répétitive dans des conditions sévères de chargement par choc. Nous présentons également des applications spécifiques de cette jauge de contrainte particulière.
\end{abstract}

\begin{abstract}
A standardized transducer that can respond to shock loading over a large stress range $(0.2$ to $50.0 \mathrm{GPa})$ is required for shock wave measurements. A cooperative program has been conducted among our laboratorles to provide a well understood and highly reproducible standardized PVDF polymer f1lm gauge to investigate stress wave loading and release. The polymer material source and electrical treatment are based on prior work by Bauer. The shock response of standardized PVDF piezoelectric stress gauges produced by SNLA/Ktech, ISL and commercially has been measured in controlled shock wave experiments using a compressed gas gun. Shock wave response measurements made in the 0.3 to 46.0 $\mathrm{GPa}$ range show excellent agreement among gauges produced by the three different facilities. These experiments demonstrated that a repeatable, well understood PVDF stress gauge can be produced if strict specifications are met. These experiments demonstrated PVDF gauges could function repeatably under severe shock loading condtions. Specific applications of this unique stress gauge are also presented.
\end{abstract}

\section{A. - INTRODUCTION}

It has been known for many years that appropriately treated polyvinylfdene flouride (PVDF) exhibits piezoelectric properties suitable for a wide varlety of applications. Because a sensor which functions under shock-compression loading is destroyed in use, these applications require a high degree of reproducibility in material constants. Various studies of PVDF film by Bauer /1-4/ have shown that conventionally avallable plezoelectric films do not exhibit sufficient reproducibility for shock applications. However, PVDF film processed to exacting specifications and poled with the Bauer inethod achieves the desired level of reproductbility.

\footnotetext{
(1) Research by Ktech Corporation supported by Sandia National Laboratories (SNLA)

${ }^{(2)}$ Work at SNLA supported by the USDOE under Contract $N^{\circ}$ DE-AC04-76DP00789
} 
In order to provide a stress gauge for widespread use in shock measurements, a cooperative effort has been initiated between Institute Saint Louis (ISL) and Sandia National Laboratories (SNLA). SNLA has been receiving technical support from Ktech Corporation to develop the Bauer poling process in the United States, while ISL has been working with Metravib Corporation in France to develop a commerclal source for the standardized PVDF gauges. Initial efforts in the cooperative program, which was started in 1982, showed agreement of independent shock wave measurements made at the two laboratories on PVDF gauges fabricated by ISL /5/. The 1nitial work was in the stress range from 1.0 to $2.2 \mathrm{GPa}$. Later work involved setting up specific material film specifications and the Bauer poling process in the United States and the Metravib Laboratory /6/. Further work showed agreement over a larger stress range and the development of an exacting controlled impact technique for evaluating PVDF stress gauges /7/. In the present paper we report the completion of our gauge standardization effort and our first measurements on shock wave response of PVDF gauges fabricated from different lots of well controlled film and poled in different laboratories using the standardized process.

Until very recently the ISL Laboratory was the only source for PVDF gauges produced by the Bauer method. As a result of the cooperative effort between our laboratories, gauge fabrication facilities have been developed in both the United States and France that can produce standardized PVDF shock compression gauges based on the patented Bauer process. The essential ingredients of the standardized gauge are a uniform high quality biaxially-stretched PVDF film and the Bauer electrical poling process.

\section{B. - GAUGE FABRICATION}

\section{MATER IAL}

The PVDF film used in the United States and France was extruded and biaxially stretched by Rhone Poulene Films in France from polymer pellets obtained from Kureha, Japan. The special film has a nominal thickness of $26 \mu \mathrm{m}$. Enough of the PVDF film has been procured for many years of gauge development and applications. This particular film was chosen because of the documented successful poling by Bauer of similar PVDF batches. Also, shock wave measurements on standardized gauges made from different PVDF lots have shown close agreement. Other PVDF films are available, but they are different from the Rhone Poulenc material and none have been subjected to the extensive testing of this material. An essential point of any shock transducer development project is a material with well defined characteristics to assure proper processing can achieve the required end result.

\section{GAUGE ELECTRODING}

The standardized stress gauge electroding process was developed after evaluating a number of metallization techniques and mask designs. Magnetron sputtering of Au or A1 over Pt produced electrodes with very good adhesion. No metal could be removed using the Scotch-tape peel test and there was no evidence of overheating the film during electroding. Other sputtering and vapor deposition techniques have shown that overheating in the film results in detrimental effects on the electrical properties of the gauge. The electrode and sensing area design utilized for the standard gauge is shown in Figure 1. The sensor area located where the two electrodes overlap is clearly the most important region of the gauge. It is critical to have sharp edge defintion for the total electroded area and accurate sensor area measurement is required for accurate shock wave measurements. Masking techniques have been developed which produce the required sharp edge definition at $100 x$ magnification, and also reduce the tendency of the PVDF to wrinkle during deposition $/ 8 /$.

\section{POLING PROCESS}

The purpose of the poling process is to induce reproductble piezoelectric polarization in the PVDF and to remove any trapped space charge. There have been many static, fleld discharge, and cyclic methods tried over the past few years, but only the Bauer process with a specific cyclic poling schedule has been proven by shockcompression tests to condition the PVDF for accurate reproducible output. The poling process incorporates the essential features as described in Bauer's U.S. patent and in the open Iiterature $/ 9 /$. 
The Baver poling procedure is specifically tallored to create a transducing element that produces charge under stress only from the plezoelectric effect and under temperature change only from the pyroelectric effect. The process, homogeneously throughout the poled region, aligns crystallites, orlents dipoles, and migrates ions and space charges out of the film. A Bauer process poling facility has been developed in Albuquerque, New Mexico, and has been shown to routinely produce high quality gauge elements with high polarization. The remanent polarization of PVDF shock gauges produced with the present United States system is the same as produced in France at ISL and Metravib, nominally $9.2+0.2 \mu \mathrm{C} / \mathrm{cm}^{2}$.

\section{C. - EXPER IMENTAL}

A standard impact loading experiment for PVDF has been developed for the SNLA 25 meter compressed gas gun. This is the facility on which the quartz and lithium niobate piezoelectric gauges were developed and has been used for a host of studies involving precisely controlled impact loading. As shown in Figure 2, the gauge element is placed directly on the impact face of a target of elther Kel-F, Z-cut quartz, 2-cut sapphire or tungsten carbide. The impactor is the same material as the target; hence, the equilibrium particle velocity is known to the precision of the impact velocity measurement, 0.1 percent. As the $z$-cut quartz and sapphire target and impactor materials remain elastic up to about 13 and $20 \mathrm{GPa}$ respectively, the gauge elements are subjected to unusually well behaved shock and release stress pulses. By the use of thin impactors, the response to release waves can be carefully studied in this arrangement. For stress greater than $20 \mathrm{GPa}$ tungsten carbide is used. In this case it is necessary to place a $25 \mu \mathrm{m}$ thick FEP Teflon film on either side of the gauge to provide electrical insulation. For stress less than $3 \mathrm{GPa} \mathrm{Kel-F}$ is used because of its lower mechanical impedance $/ 10 \%$.

Various electronic recording arrangements have been investigated. For ease in data reduction, high speed digitizers provide the best recording means. Because of the very fast loading achleved, a high digitizing rate was required to track the detall In the PVDF response. Lecroy 6880 digitizers which digitize at a rate of $0.742 \mathrm{~ns}$ and have a recording wincow of $7.4 \mu \mathrm{s}$ were selected. The LeCroy digitizers provide the preferred recording method.

To provide measurements of the signals at different sensitivities, our arrangement uses two low-loss coaxlal cables rather than a single cable on which the signals are transmitted to several digitizers. The electrical currents produced upon impact from electrode areas of about $0.1 \mathrm{~cm}^{2}$ range from about 1 to 30 amperes in the present experiments. To reduce the signal levels to acceptable values, current-viewing resistors with resistances between 0.025 to 0.2 ohm are connected to the gauge electrodes. Further signal level reduction, if desired, is accomplished with microwave dividers placed at the inputs to the digitizers.

\section{D. - RESULTS}

The joint program of PVDF gauge development conducted over the last 6 years has resulted in a set of quantitative specifications describing the standardized stress gauge. The specifications are shown in Table 1 relative to materlal, electroding and poling parameters that must be achieved to produce a repeatable high fidelity shock wave sensor. The normal hysteresis loop listed in Table 1 is shown in Figure 3 for gauges produced at the three different facilfties. The excellent agreement in remanent polarization and hysteresis loop characteristics show the reproducibility of PVDF gauges made to exacting standards. While the program is ongolng, the results to date cover a wide range of parameters relative to gauge area and shock stress as shown in Table 2. Of primary importance in Table 2 is the fact that the same remanant polarization, which has been shown in previous work to be of primary importance in producing a repeatable shock transducer, has been achieved in the three different iaboratories using essentially the same gauge fabrication processes. Also shown in Table 2 is a wide range of shock-compression loading to which the gauges have been exposed. This dynamic range is an order of magnitude larger than any previously avallable plezoelectric shock gauge. 
TABLE 1. Standardized PVDF gauge speciffcations.

Material

Electrode

Poling

Physical-Geometric
Blaxial stretched $25 \mu \mathrm{m}$ (Rhone Poulenc).

Sputtered (Au $2500 \AA$ A over Pt $500 \AA$ A).

Crossed lead strip sensing area.

Remanent polarization $9.2+0.2 \mu \mathrm{C} / \mathrm{cm}^{2}$. Normal hysterests loop.

Quantitative definition of all parameters.

TABLE 2. PVDF gauge parameters.

\begin{tabular}{cccc}
\hline $\begin{array}{c}\text { Gauge } \\
\text { Fabrication }\end{array}$ & $\begin{array}{c}\text { Gauge Area } \\
\left(\mathrm{cm}^{2}\right)\end{array}$ & $\begin{array}{c}\text { Remanent Polarization } \\
\left(\mu \mathrm{C} / \mathrm{cm}^{2}\right)\end{array}$ & $\begin{array}{c}\text { Controlied Shock } \\
\text { Loading }(\mathrm{GPa})\end{array}$ \\
\hline ISL & $\begin{array}{c}0.01 \\
1 \mathrm{~mm} \times 1 \mathrm{~mm}\end{array}$ & 9.1 & $7-15$ \\
SNLA/Ktech & $\begin{array}{c}0.09 \\
3 \mathrm{~mm} \times 3 \mathrm{~mm}\end{array}$ & 9.1 & $0.3-46$ \\
Metravib & $\begin{array}{l}0.01 \\
1 \mathrm{~mm} \times 1 \mathrm{~mm}\end{array}$ & 9.1 & $0.7-35$
\end{tabular}

A comparison of results from different gauges shock loaded using the controlled impact technique are shown in Figure 4. The shock compression data shown in Figure 4 were generated at SNLA and ISL. The results indicate minimal scatter, with similar responses being obtained for the gauges produced in France and the United States. Limited data of this type have been obtained previously; however, in the current study we have expanded the applicable stress range up to $46 \mathrm{GPa}$ where the gauge is still functioning properly. The ability to produce repeatable PVDF shock transducers in the different laboratories to exacting specifications now provides the avallability for general application of the shock transducers for unique measuring requirements.

Some gauges were studied with the positive electrode on the impact surface to investigate the influence of gauge electrical orientation on output current. Data reported here were obtained with the standard orlentation used by Bauer in which the negative electrode is placed on the impact surface. It appears there is an electrical polarity effect which must be considered.

Standardized PVDF gauges have been utilized in pulsed Iaser experiments which allowed stress measurements to be made within $30 \mu \mathrm{m}$ of the deposition region with fluxes ranging to $10^{8} \mathrm{~W} / \mathrm{cm}^{2}$. Two PVDF records from these experiments are shown in Figure 5. The ability to make small sensors in the range of $0.01 \mathrm{~cm}^{2}$ and the inherent flexibility of the PVDF shock sensor, primarily its large signal to noise ratio, allow these data to be obtained in an extremely harsh electrical environment, which further illustrates the flexibility and range of the PVDF gauge.

\section{E. - CONCLUSION}

The present work has succeeded in developing standardized PVDF gauges which show reproduclbility in three different laboratories to the same specifications. Controlled shock loading of these gauges has proven the ability to make PVDF stress gauges to quantitative specifications. These specifications have now been defined and rigorously tested. The second important accomplishment is that the standardized PVDF gauge has been evaluated from 0.3 to $46 \mathrm{GPa}$ shock pressure loading and provided 
repeatable, well understood response. The large dynamic range of this transducer has been shown to be unique and provides a shock wave measurement tool that has previously not been available to the technical community. The many unique positive attributes of the PVDF shock gauge are expected to have a revolutionary impact on stress gauging technology.

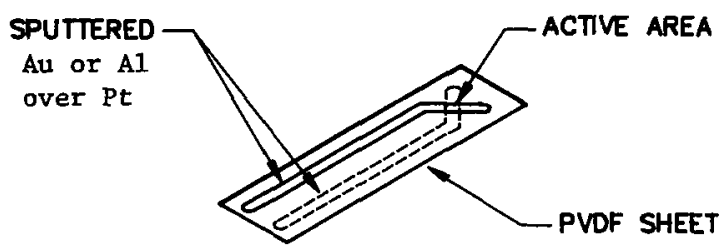

Fig. 1. Standardized PVDF shock gauge configuration.

\section{IARGEI ASSEMBLY RROJECTILE}

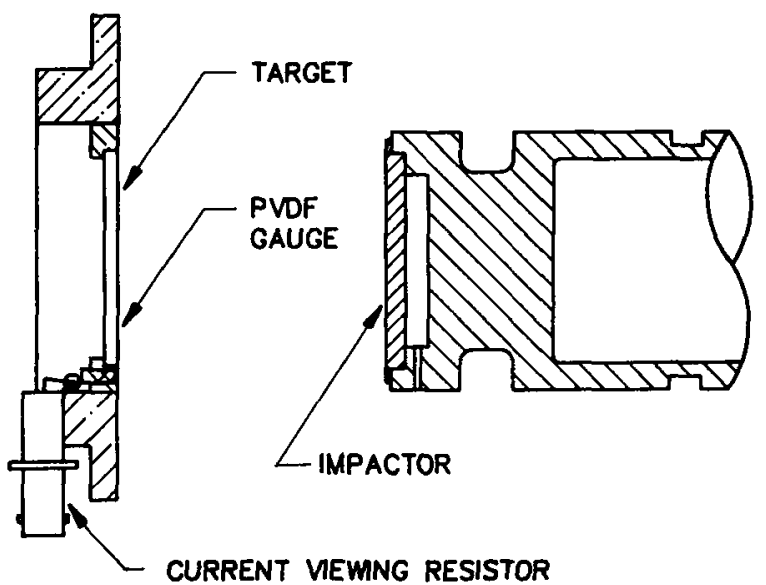

Fig. 2. Impact loading configuration for controlled shock loading of standardized PVDF gauges. 


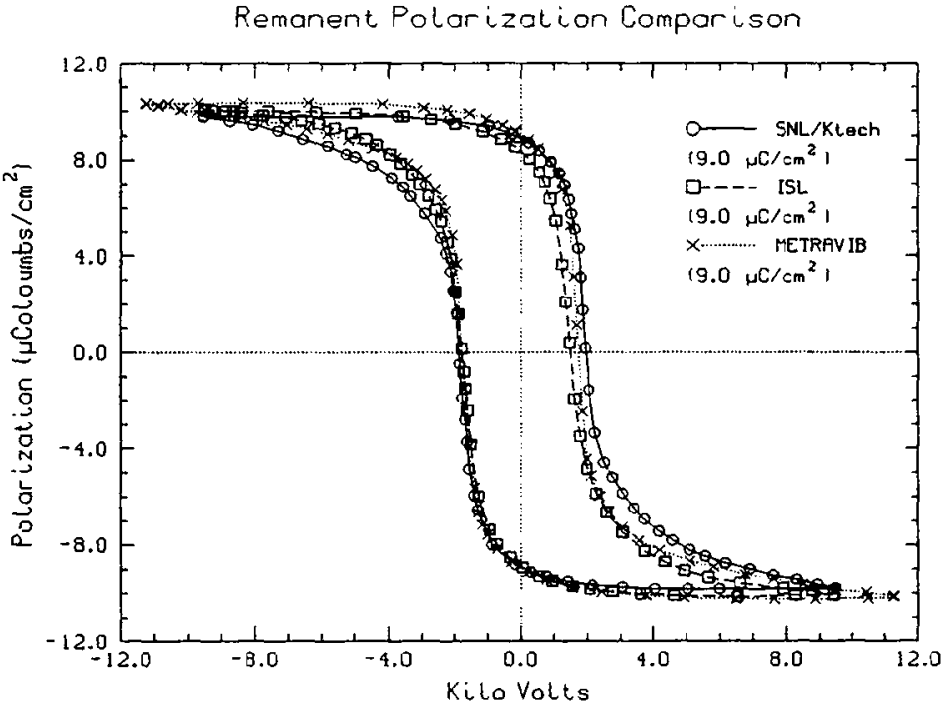

Fig. 3. Hysteresis loop comparison for SNLA/Ktech, ISL and Metravib standardized PVDF shock gauges.

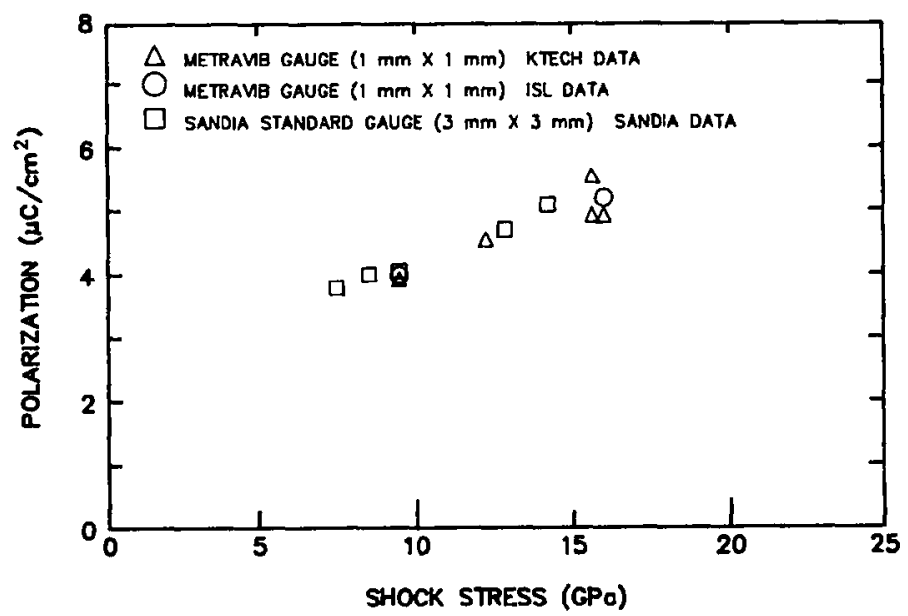

Fig. 4. PVDF gauge charge as a function of shock stress. (Preliminary data, detailed data analysis in process.) 


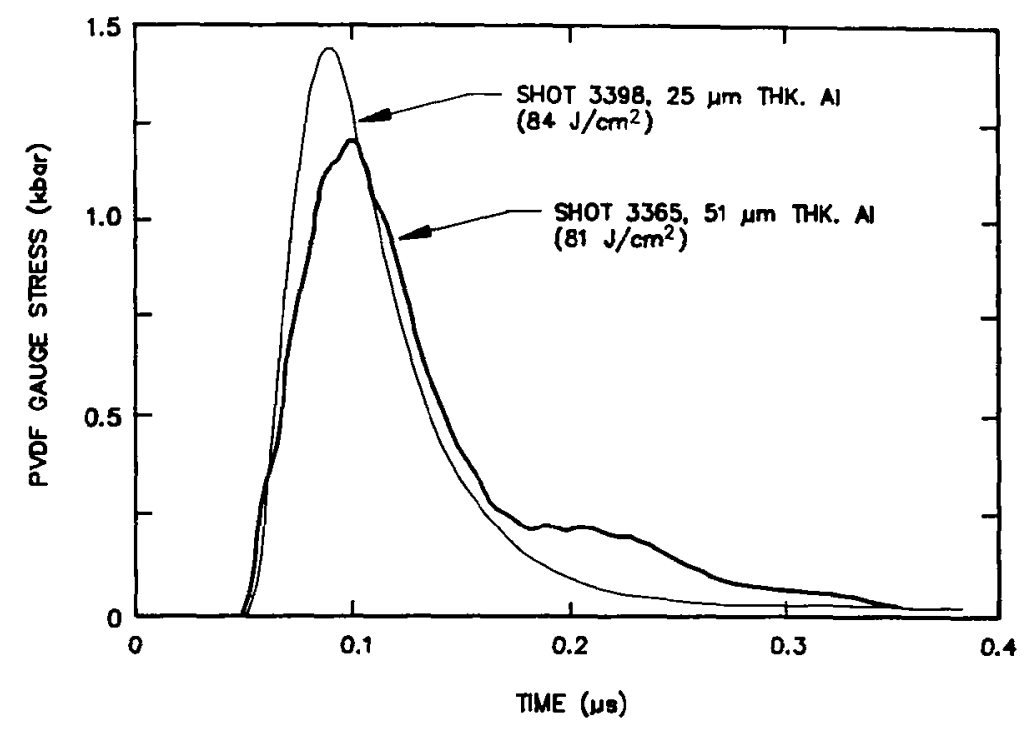

Fig. 5. PVDF stress gauge data from pulsed laser experiments (SPRITE).

\section{REFERENCES}

1/ F. Bauer, Behavior of Ferroelectric Ceramics and PVF2 Polymers Under Shock Loading, in Shock Waves in Condensed Matter-1981, eds. W.J. Nellis, L. Seaman, R. A. Graham, American Institute of Physics (1982) 251.

12/ F. Bauer, Piezoelectric and Electric Properties of PVF 2 Polymers Under Shock Wave Action: Application to Shock Transducers, in Shock Waves in Condensed Matter-1983, eds. J.R. Asay, R. A. Graham, G.K. Straub, North Holland (1984) 225.

13/ F. Bauer, PVF2 Polymers: Ferroelectric Polarization and Piezoelectric Properties Under Dynamic Pressure and Shock Wave Action, Ferroelectrics 49:231 (1983).

14/ F. Bauer, Properties and High Pressure Shock Loading Response of Poled Ferroelectric PVF 2 Polymer Gauges, in: Techniques and Theory of Stress Measurements for Shock Wave Applications, eds. R. B. Stout, F. R. Norwood, M. E. Fourney (ASME, New York, 1987) ig-28.

15/ L.M. Lee, W. D. Whlliams, R.A. Graham, F. Baver, in Shock Waves in Condensed Matter, Y.M. Gupta, ed., Plenum Press, New York (1986) 497.

16/ D. J. Fogelson, L. M. Lee, D.W. Gilbert, W.R. Conley, R. A. Graham, R. P. Reed, and F. Bauer, Fabrication of Standardized Piezoelectric Polymer Shock Gauges by the Bauer Method, in Shock Waves in Condensed Matter-1987, Elsevier Science Publishers B.V. (1988) 615 .

/7/ R. A. Graham, L.M. Lee, F. Bauer, Response of Bauer Plezoelectric Polymer Stress Gauges (PVDF) to Shock Loading, in Shock Waves in Condensed Matter-1987, Elsevier Sclence Publishers B.V. (1988) 619.

/8/ R. P. Reed, Recent Developments in Piezoelectric Polymer Stress Gauges, in: Proceedings, The Range Comanders Cauncil, Instrumentation/Transducer Committee, 14th Transducer Workshop, ed. S.F. Kuehn, Colorado Springs, Co, 16-18 June 1987.

19/ F. Bauer, method and Device for Polarizing Ferroelectric Materials, U.S. Patent 4,611, 260, September 9, 1986.

/10/ LASL Shock Hugoniot Data, Stanley P. Marsh, ed., University of California Press, Berkely, CA. 